\title{
The combined use of a nonabrasive, activator-containing toothpaste and a light emitting diode device improves the onset time of tooth whitening
}

\author{
Stephan Bielfeldt ${ }^{1}$, Ismaela Foltran ${ }^{2}$, Arne Böhling ${ }^{1}$, Caroline Manger ${ }^{1}$, \\ Klaus-Peter Wilhelm ${ }^{1}$
}

Correspondence: Ms. Caroline Manger

Email: cmanger@proderm.de
1proDERM Institute for Applied Dermatologica Research GmbH, Schenefeld, Hamburg, Germany, IIncos Cosmetica Industriale s.r.l, Castello d`Argile Bologna, Italy

\section{ABSTRACT}

Objective: The objective of this randomized clinical study was to assess the onset time of the whitening effect of a combined use of a nonabrasive, activator-containing toothpaste and a light emitting diode (LED) device, compared to that of the toothpaste alone. Materials and Methods: A nonabrasive, activator-containing toothpaste was used twice daily alone or combined with an LED device for 15 days. The onset of the tooth whitening effect was evaluated through tooth color $\left(\mathrm{a}^{*} \mathrm{~b}^{*}\right.$, CIELAB) and tooth whiteness (WIO) by image analysis of standardized images. Local tolerance was assessed at days 1,8 , and 15 . Results: On day 8 , a significant $(P=0.003)$ tooth whitening effect compared to day 1 was observed with the toothpaste and the LED device, sustaining until the end of the study. Whitening using the toothpaste alone was significant compared to day 1 after 15 days, only. One subject reported mild redness, itching, and burning on day 1 on the gum of the lower jaw that was possibly related to with the toothpaste. The subject withdrew from the study. No adverse event was reported in the group using the LED device. Conclusion: Both tooth whitening methods had a significant whitening effect after 15 days of use. However, the onset of whitening was significantly faster when using the nonabrasive, activator-containing toothpaste combined with an LED device. The toothpaste and LED device were both safe.

Key words: Light emitting diode-device, nonabrasive toothpaste, photoactivation, tooth color, tooth whitening

\section{INTRODUCTION}

White, immaculate teeth are an important consumer desire worldwide. Therefore, discolored teeth represent an esthetic problem, particularly when affecting the maxillary anterior teeth. ${ }^{[1]}$ The desire is highlighted by various over-the-counter (OTC) whitening products available on the market as toothpaste or mouthwashes. ${ }^{[2]}$

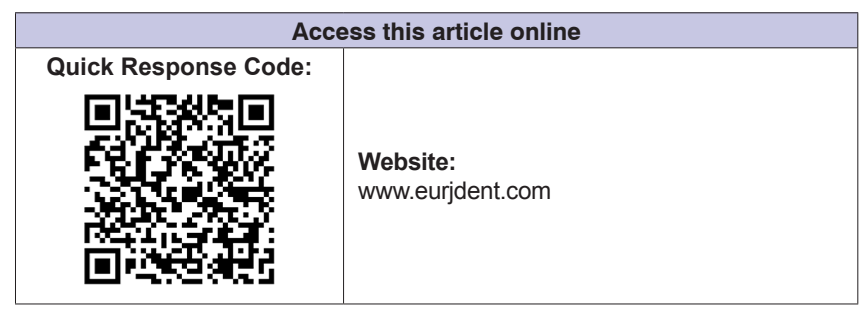

OTC tooth whitening products usually contain low levels of whitening agents such as 3\%-6\% hydrogen peroxide and abrasives, as well as chemicals to maximize cleaning. ${ }^{[3-10]}$ They are usually self-applied

This is an open access journal, and articles are distributed under the terms of the Creative Commons Attribution-NonCommercial-ShareAlike 4.0 License, which allows others to remix, tweak, and build upon the work non-commercially, as long as appropriate credit is given and the new creations are licensed under the identical terms.

For reprints contact: reprints@medknow.com

How to cite this article: Bielfeldt S, Foltran I, Böhling A, Manger C,
Wilhelm KP. The combined use of a nonabrasive, activator-containing
toothpaste and a light emitting diode device improves the onset time of
tooth whitening. Eur J Dent 2018;12:329-33.
DOI: $10.4103 /$ ejd.ejd_167_18


to the teeth via gum shields, strips, or other. Even though efficacious, their prolonged use may also lead to an undesirable increase of tooth surface wear, affecting not only sound enamel surfaces but also, and more significantly, mineralizable incipient caries, and erosion lesions. ${ }^{[11-13]} \mathrm{A}$ wide range of tooth whitening toothpaste formulations is available. These formulations contain plant extracts such as papain, bromelain, extracts from arctic lichen or the recently developed agent with optical properties, blue covarine and are generally considered less aggressive to the teeth. ${ }^{[10,14,15]}$

One method for assessing color of teeth is chromametry, based on the color expression regarding the Commission internationale de l'Eclairage (CIE) Lab color space. This space represents a uniform color space, with equal distances corresponding to equally perceived color differences. In this three-dimensional color space, the three axes are $L^{*}, a^{*}$ and $b^{*}$.

A very convenient method to measure tooth color consists in the use of noncontact camera-based digital imaging and analysis systems. ${ }^{[16-20]}$ For this, an image of the anterior teeth is captured under controlled light conditions by a digital camera, using suitable calibration tiles or standards, and then subsequently analyzed via computer software to determine the color of the individual teeth, expressing them regarding CIE Lab values. ${ }^{[13]}$ A further sensitive parameter used to assess the whiteness of teeth is the whiteness index (WIO). ${ }^{[21]}$

The objective of this study was to assess the onset time of a commercially available nonabrasive photoactivated tooth-whitening paste (BlanX ${ }^{\circledR}$ White Shock ${ }^{\circledR}$, Coswell s.p.a, Funo, Italy) containing arctic lichen (Cetraria islandica), titanium dioxide and hydroxyapatite as an activator (Actilux ${ }^{\circledR}$ Incos Cosmeceutica Industriale s. r. 1., Funo, Italy) and an adjunctively-used light emitting diode (LED) device compared to the tooth-whitening paste alone, using an imaging and analysis method.

\section{MATERIALS AND METHODS}

\section{Settings}

This randomized, investigator-blind study was conducted in February 2016 at one study site in Hamburg, Germany.

The study received ethics committee approval (Freiburger ethics commission international, code $017 / 1070$ ) and was conducted according to the main principles of good clinical practices and by the principles of the Declaration of Helsinki and local legal requirements for the conduct of cosmetic studies.

Each subject who participated in this study was informed verbally and in written form about the study and signed the informed consent form before inclusion and before any study procedure.

\section{Study population}

Suitable participants for this study had to be aged between 18 and 70 years and had to have eight intact, naturally healthy, slightly yellow front teeth with a regular stain. Moreover, participants had to respect average oral hygiene, defined as twice-daily brushing of the teeth. Pregnant or lactating women, participants addicted to drugs or alcohol, with a known acquired immunodeficiency syndrome or hepatitis infection, or a known allergy to one of the compounds of the toothpaste, or who were wearing tooth jewelry, fixed braces on or oral piercings near the front teeth were excluded from this study. Furthermore, participants with an ongoing dental or any other medical treatment of the oral cavity, or participants who had undergone a tooth whitening procedure within 6 months prior to the start of the study or during the study, or who had an antibacterial treatment of the oral cavity 2 weeks prior to or during the study, were not allowed to participate.

\section{Procedures}

Participants who signed the informed consent attended three study visits (day 1, 8 and 15).

\section{Baseline assessments}

At day 1 / baseline, participants were asked to brush their teeth with their own toothbrush and toothpaste. A dentist assessed their eligibility according to the inclusion and exclusion criteria. Participants were asked not to use any other cosmetic tooth whitening products during the study. After the first brushing of the teeth, photographs of the four anterior front teeth were taken.

\section{Product use}

Participants were randomized at day 1 to either use the toothpaste alone or together with the LED device. Participants received the toothpaste and a toothbrush (manual, medium softness) for the duration of the study and were not allowed to use any other oral hygiene product, including toothpaste, chewing gum, mouthwash, or spray. Participants were instructed to apply $1 \mathrm{~cm}$ of the test toothpaste to the provided brush and to brush their teeth for 
2 min according to their usual brushing habits. After rinsing their mouth, participants randomized into the toothpaste-plus-LED group were instructed to hold the device in front of their front teeth for $3 \mathrm{~min}$, at a distance of approximately $3 \mathrm{~cm}$. The first application of the test products took place in the morning of day 1 at the study site under the supervision of a technician. Then, the application was performed by the participants twice daily (in the morning and the evening) at home.

On day 8 and 15, participants were asked to use the test toothpaste and LED device as described above at the study site before the image was taken.

\section{Efficacy and safety assessments}

Standardized photographs of the four anterior teeth were taken on day 1 (before use of the test products), day 8 and 15 in a photo studio specifically designed for high definition clinical photography (USR-CliP). A camera with a high resolution 50 megapixels (H5D-50c, Hasselblad, Göteborg, Sweden) and a professional flash system containing a Broncolor Scoro A2 flash generator, two Broncolor Picolight flashes at the sides and a central Broncolor ringflash C (Bron Elektronik AG Allschwil, Switzerland) was used to homogeneously illuminate the front teeth. For reproducible positioning of volunteers, a chin rest was used. The color of all visible front teeth was evaluated individually with a specifically developed image analysis software (PIAS Teeth, proDERM Image Analysis Software, proDERM, Hamburg, Germany). The average color was reported as CIELAB $\left(\mathrm{L}^{*}, \mathrm{a}^{*}, \mathrm{~b}^{*}\right)$-values and whiteness WIO was assessed.

WIO was calculated according to the following formula:

$\mathrm{WIO}=\mathrm{Y}+1075.012(\mathrm{xn}-\mathrm{x})+145.516(\mathrm{yn}-\mathrm{y})$.

Where $\mathrm{Y}$ is the luminance value and $(\mathrm{x}, \mathrm{y})$ and $(\mathrm{xn}, \mathrm{yn})$ are the chromaticity coordinates of the sample and the reference white, respectively. A decrease of tooth color values and an increase of WIO value can be interpreted as increased tooth whiteness.

Local tolerance was assessed at all the study visits.

\section{Statistics}

Due to the explorative character of the study, no adjustment for multiplicity was made.

The comparison of assessment times was performed using a paired $t$-test on raw data between day 1 , day
8 and day 15 for $\mathrm{a}^{*}, \mathrm{~b}^{*}$ and WIO values. Comparisons between treatments were made using independent $t$-tests for each assessment time point on differences to baseline for $a^{*}, b^{*}$ and WIO. Results of the questionnaires were analyzed using a binomial test to assess the difference in frequencies of agreement and disagreement answers.

A significance level of 0.05 (alpha) was chosen.

Statistical analyses were performed using commercially available statistics software (SAS for Windows, version 9.4, SAS Institute Inc., Cary, USA).

\section{RESULTS}

\section{Demographic data and baseline assessments}

A total of 54 participants were enrolled in the study. Four withdrew: one due to a test product-related adverse event and three for administration reasons. Data from 50 participants (15 [30\%] male and $35[70 \%]$ female participants with a mean age of $44.4 \pm 12.8$ years) were used for the data analysis. In each treatment group, 25 participants completed the study.

\section{Image analysis}

Using the test toothpaste and the LED device resulted in a statistically significant quicker onset of tooth whitening as early as day 8 , compared to participants randomized to the toothpaste-only group [Figure 1a-c].

In the group that used the LED device, $a^{*}$ and $b^{*}$ had significantly decreased versus Day $1\left(\Delta \mathrm{a}^{*}:-0.33\right.$, $P=0.001$ and $\left.\Delta \mathrm{b}^{*}:-0.62, P=0.004\right)$ while WIO had significantly increased ( $\triangle \mathrm{WIO}: 5.53, P<0.001)$ at day 8 , sustaining until day $15\left(\Delta \mathrm{a}^{*}:-0.62, \Delta \mathrm{b}^{*}\right.$ : -0.46 , $P=0.037$ and $\Delta$ WIO: $5.39, P<0.001)$. For participants using the toothpaste only, significant results versus day 1 were obtained only after 15 days $\left(\Delta \mathrm{a}^{*}\right.$ : -0.73 , $P<0.001, \Delta b^{*}:-0.50, P=0.016, \Delta$ WIO: $\left.5.85, P=0.003\right)$. The difference between both study groups was not statistically significant, at any time point or for any parameter.

\section{Safety}

Two participants reported an adverse event each. One (mild redness, itching and burning on day 1 on the gum of the lower jaw) was considered as being probably related to the tested toothpaste; the subject withdrew from the study. The second event was considered unrelated to the test products; the subject continued the study. 


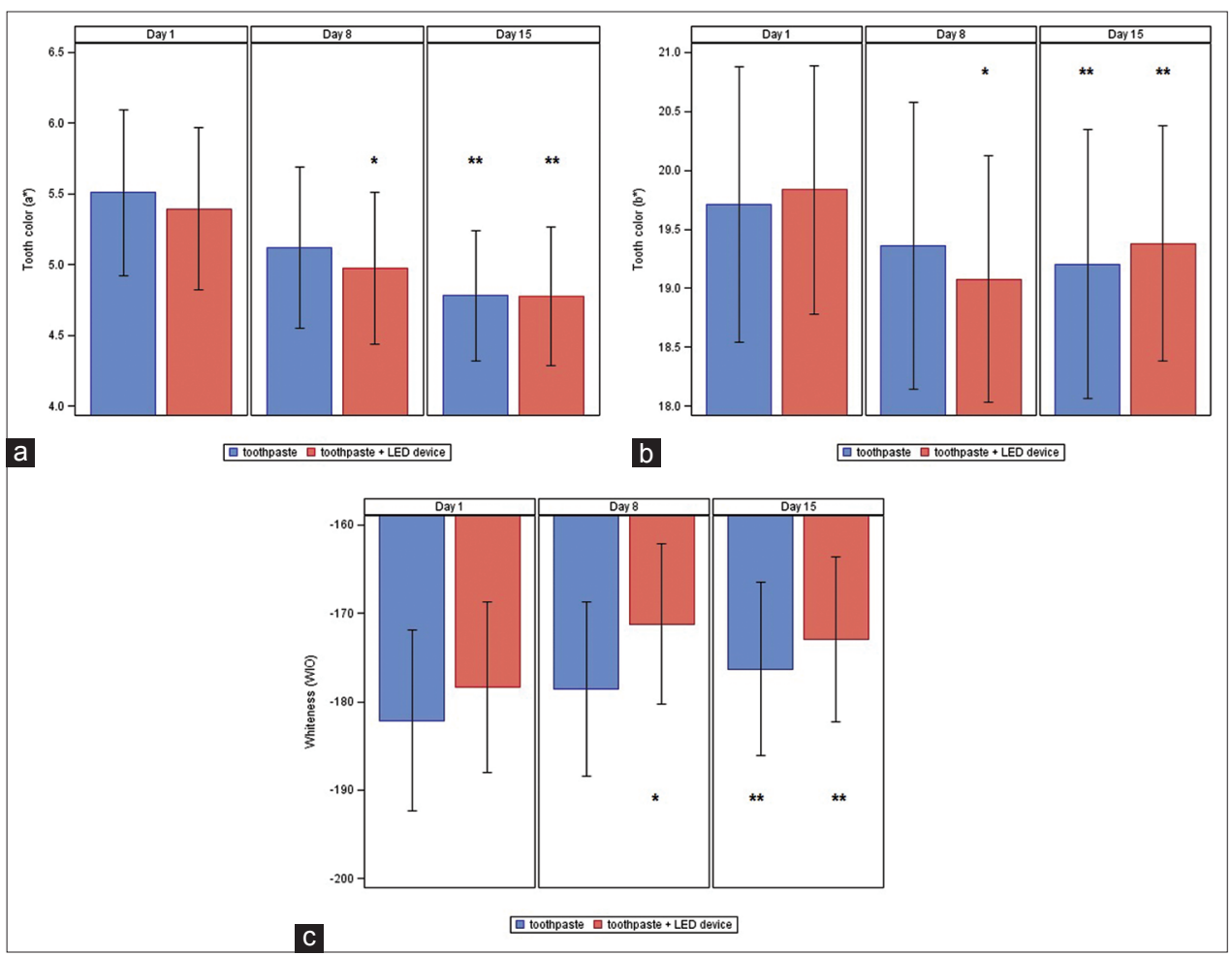

Figure 1: (a) Mean values for tooth color $\left(\mathrm{a}^{*}\right) ;{ }^{*} P=0.001,{ }^{* *} P<0.001$. (b) Mean values for tooth color $\left(\mathrm{b}^{*}\right) ;{ }^{*} P=0.004,{ }^{* *} P=0.016,{ }^{* * *} P=0.037$. (c) Mean values for tooth whiteness (WIO); ${ }^{*} P<0.001,{ }^{* *} P=0.003,{ }^{* * *} P<0.001$

\section{DISCUSSION}

The objective of this study was to assess the onset time of the whitening effect of the activator-containing toothpaste combined with an LED device compared to that of the whitening toothpaste alone.

Results from 50 participants showed that the additional use of a LED device significantly improves the onset time of tooth whitening, compared to the classical use of the toothpaste: a significant tooth whitening effect $(P<0.05)$ using the combined procedure was observed as early as 8 days after the start of the study, sustaining until the end of the study on day 15. Conversely, a significant difference of tooth whitening from day 1 using the toothpaste alone could only be demonstrated after 15 days of continual, twice-daily use.

The cold-light bleaching technique assessed in the present study uses blue light (wavelength between $480 \mathrm{~nm}$ and $520 \mathrm{~nm}$ ). The device is equipped with a filter that excludes the infrared (wavelength $\lambda>750 \mathrm{~nm}$ ) and the harmful ultraviolet $(\lambda<380 \mathrm{~nm})$. To the best of our knowledge, only one in vitro study using a combined use of a LED device and a tooth whitening preparation containing 35\% hydrogen peroxide was conducted. ${ }^{[22]}$ Whitening results were promising, but the authors also observed a demineralization in the enamel surface considered as being related to the use of an acidic peroxide-containing bleaching agent but not related to the use of cold-light. Till date, no investigation has been performed to assess in vivo the combined effect of cold blue light and a tooth whitening paste containing no abrasive or aggressive bleaching or carbamide peroxide compounds such as hydrogen peroxide.

The whitening toothpaste used in the present study does not contain any peroxide containing agent, nor does it contain abrasive compounds. Its efficacy is based on the activator $\left(\right.$ ActiluX $\left.{ }^{\circledR}\right)$ and extracts from the arctic lichen Cetraria islandica. This lichen has been reported to have antioxidant, antimicrobial, genotoxic, and anticancer properties. ${ }^{[23]}$ In the oral cavity, extracts of Cetraria islandica limit naturally the proliferation of the buccal microbes, triggering buccal infections, and extrinsic tooth staining. ${ }^{[24,25]}$ Actilu $X^{\circledR}$ is a patented combination of titanium dioxide and hydroxyapatite microcrystals. Titanium dioxide is known as an intensely white pigment. It has a high refractive index and is widely used in toothpaste formulations. Hydroxyapatite is a lattice of calcium and is used in tooth and bone engineering. ${ }^{[26,27]}$ Coating the teeth and slipping into tiny cracks, it breaks down in response to acid, thereby protecting the tooth enamel from decay and cavities, and hence prevents from sensitivity. In addition, it provides a source of calcium and phosphate ions which, 
combined with fluoride, helps to remineralize the tooth surface. The combined use of this novel toothpaste and of the LED device which activates the tooth whitening effect of titanium dioxide, allows for a fast-onset of the tooth whitening effect, while the sustained activity of hydroxyapatite and antimicrobial activity of Cetraria islandica improves tooth protection and the balance of the natural buccal microflora responsible for the extrinsic staining. However, as is the case for every tooth whitening procedure, the results obtained are not irreversible. Consumption of food or beverages, or medication, may reinitiate tooth staining. Therefore, daily buccal care and limitation of extrinsic stain triggers must be considered as prolonging the whitening results obtained.

\section{CONCLUSION}

Both tooth whitening methods have a whitening effect after 2 weeks of use confirming the efficacy of the toothpaste. However, the onset of whitening was faster when using the toothpaste combined with an LED device, thereby confirming the synergistic effect of the LED device and the nonabrasive, activator-containing toothpaste.

\section{Acknowledgment}

The authors would like to thank Karl Patrick Göritz (Scientifc and Medical Writing Service, Les Issambres, France) for the preparation of this manuscript and helpful discussions.

The study was completely financed by the Sponsor (Incos Cosmetica Industriale s.r.l., Castello D'Argile BO, Italy). The authors do not have any financial interest in the companies whose materials are included in this article.

\section{Financial support and sponsorship}

Nil.

\section{Conflicts of interest}

There are no conflicts of interest.

\section{REFERENCES}

1. Alshara S, Lippert F, Eckert GJ, Hara AT. Effectiveness and mode of action of whitening dentifrices on enamel extrinsic stains. Clin Oral Investig 2014;18:563-9.

2. Majeed A, Farooq I, Grobler SR, Rossouw RJ. Tooth-bleaching: A review of the efficacy and adverse effects of various tooth whitening products. J Coll Physicians Surg Pak 2015;25:891-6.

3. Horn BA, Bittencourt BF, Gomes OM, Farhat PA. Clinical evaluation of the whitening effect of over-the-counter dentifrices on vital teeth.
Braz Dent J 2014;25:203-6.

4. Soares CN, Amaral FL, Mesquita MF, Franca FM, Basting RT, Turssi $\mathrm{CP}$. Toothpastes containing abrasive and chemical whitening agents: Efficacy in reducing extrinsic dental staining. Gen Dent 2015;63:e24-8.

5. Schemehorn BR, Moore MH, Putt MS. Abrasion, polishing, and stain removal characteristics of various commercial dentifrices in vitro. J Clin Dent 2011;22:11-8.

6. Torres CR, Perote LC, Gutierrez NC, Pucci CR, Borges AB. Efficacy of mouth rinses and toothpaste on tooth whitening. Oper Dent 2013;38:57-62.

7. Joiner A, Philpotts CJ, Ashcroft AT, Laucello M, Salvaderi A. In vitro cleaning, abrasion and fluoride efficacy of a new silica based whitening toothpaste containing blue covarine. J Dent 2008;36 Suppl 1:S32-7.

8. Meyers IA, McQueen MJ, Harbrow D, Seymour GJ. The surface effect of dentifrices. Aust Dent J 2000;45:118-24.

9. Joiner A. The bleaching of teeth: A review of the literature. J Dent 2006;34:412-9.

10. Collins LZ, Maggio B, Liebman J, Blanck M, Lefort S, Waterfield P, et al. Clinical evaluation of a novel whitening gel, containing $6 \%$ hydrogen peroxide and a standard fluoride toothpaste. J Dent 2004;32 Suppl 1:13-7.

11. Kielbassa AM, Gillmann L, Zantner C, Meyer-Lueckel H, Hellwig E, Schulte-Mönting J. Profilometric and microradiographic studies on the effects of toothpaste and acidic gel abrasivity on sound and demineralized bovine dental enamel. Caries Res 2005;39:380-6.

12. Attin T, Koidl U, Buchalla W, Schaller HG, Kielbassa AM, Hellwig E. Correlation of microhardness and wear in differently eroded bovine dental enamel. Arch Oral Biol 1997;42:243-50.

13. Pickles MJ. Tooth wear. Monogr Oral Sci 2006;19:86-104.

14. Patil PA, Ankola AV, Hebbal MI, Patil AC. Comparison of effectiveness of abrasive and enzymatic action of whitening toothpastes in removal of extrinsic stains - A clinical trial. Int J Dent Hyg 2015;13:25-9.

15. Kim MK, Park H, Oh TJ. Antibacterial and antioxidant capacity of polar microorganisms isolated from arctic lichen Ochrolechia sp. Pol J Microbiol 2014;63:317-22.

16. Gerlach RW, Gibb RD, Sagel PA. A randomized clinical trial comparing a novel $5.3 \%$ hydrogen peroxide whitening strip to $10 \%, 15 \%$, and $20 \%$ carbamide peroxide tray-based bleaching systems. Compend Contin Educ Dent Suppl 2000;29:S22-8.

17. Sagel PA, Jeffers ME, Gibb RD, Gerlach RW. Overview of a professional tooth-whitening system containing $6.5 \%$ hydrogen peroxide whitening strips. Compend Contin Educ Dent 2002;23:9-15.

18. Bentley C, Leonard RH, Nelson CF, Bentley SA. Quantitation of vital bleaching by computer analysis of photographic images. J Am Dent Assoc 1999;130:809-16.

19. Guan YH, Lath DL, Lilley TH, Willmot DR, Marlow I, Brook AH. The measurement of tooth whiteness by image analysis and spectrophotometry: A comparison. J Oral Rehabil 2005;32:7-15.

20. Jarad FD, Russell MD, Moss BW. The use of digital imaging for colour matching and communication in restorative dentistry. Br Dent J 2005;199:43-9.

21. Luo W, Westland S, Brunton P, Ellwood R, Pretty IA, Mohan N. Comparison of the ability of different colour indices to assess changes in tooth whiteness. J Dent 2007;35:109-16.

22. Shi XC, Ma H, Zhou JL, Li W. The effect of cold-light-activated bleaching treatment on enamel surfaces in vitro. Int J Oral Sci 2012;4:208-13.

23. Grujičić D, Stošić I, Kosanić M, Stanojković T, Ranković B, Milošević-Djordjević O. Evaluation of in vitro antioxidant, antimicrobial, genotoxic and anticancer activities of lichen cetraria islandica. Cytotechnology 2014;66:803-13.

24. Li Y, Zhang Q, Zhang F, Liu R, Liu H, Chen F. Analysis of the microbiota of black stain in the primary dentition. PLoS One 2015;10:e0137030.

25. Ronay V, Attin T. Black stain - A review. Oral Health Prev Dent 2011;9:37-45.

26. Zhou H, Lee J. Nanoscale hydroxyapatite particles for bone tissue engineering. Acta Biomater 2011;7:2769-81.

27. Lim BK, Sun F, Ryu SC, Koh K, Han DW, Lee J, et al. Hydroxyapatite coating on damaged tooth surfaces by immersion. Biomed Mater 2009;4:025017. 